\title{
UNIVERSITY OF TORONTO
}

LIBRARIES

\section{CPOJ}

\section{Canadian Prosthetics \& Orthotics Journal}

All articles are permanently available online to the public without restrictions or subscription fees. All articles are free to be used, cited, and distributed, on condition that appropriate acknowledgment is included. Authors are the copyright holders of their original contributions and grant the Canadian Prosthetics \& Orthotics Journal (CPOJ) a license to publish the article and identify itself as the original publisher. CPOJ articles are licensed under the Creative Commons Attribution 4.0 International License.

CPOJ Website: https://jps.library.utoronto.ca/index.php/cpoj/index

Editorial Office: cpoj@online-publication.com

ISSN 2561-987X

VOLUME 1, ISSUE 1 


\title{
RESEARCH ARTICLE
}

\section{A FEASIBILITY STUDY TO INVESTIGATE IF THERE IS A CORRELATION BETWEEN SOFT TISSUE DEFORMATION AND ACOUSTIC EMISSION}

\author{
Buis $\mathrm{A}^{1^{*}}$, Guarato $\mathrm{F}^{2}$, Law $\mathrm{J}^{1}$, Ralston $\mathrm{Z}^{1}$, \& Courtney $\mathrm{A}^{3}$ \\ ${ }^{1}$ Department of Biomedical Engineering, University of Strathclyde, Glasgow, Scotland, UK. \\ ${ }^{2}$ Department of Electronic and Electric Engineering, University of Strathclyde, Glasgow, Scotland. UK. \\ ${ }^{3}$ The London Orthotic Consultancy Ltd, Kingston-Upon-Thames, Greater London, England, UK.
}

\section{ABSTRACT}

BACKGROUND: Background: Acoustic emission from structures subject to external loads can be monitored to detect internal damage before destruction occurs. It is hypothesised that deformation of soft tissue will emit acoustic signals which may aid early detection of deep tissue injury, particularly in the lower limb amputee population. No previous studies have applied this method to biological soft tissue.

OBJECTIVE: To determine if skeletal muscle tissue produced measurable acoustic emission during dynamic tensile loading with the aim to establish a reliable biomarker for lower limb prosthetic socket fit quantification and prosthetic health.

STUDY DESIGN: Experimental study design.

METHODOLOGY: In this research article, Sus scrofa domesticus (pork) muscle and Gallus gallus domesticus (chicken) muscle specimens (10mm width $\mathrm{x} 45 \mathrm{~mm}$ height $\mathrm{x} 4 \mathrm{~mm}$ depth) were submerged into saline baths while an Instron testing machine applied displacement controlled tensile loads. Time stamped, load, displacement and acoustic signal (hydrophone) data was collected.

FINDINGS: The pork muscle was tested to failure being subject to tensile load. Prior to failure, no peaks were found in the amplitude or frequency of the acoustic signal to indicate that either tissue deformation or failure was occurring. Data gathered during chicken muscle testing was inconclusive.

CONCLUSIONS: Results displayed that tensile testing of pork intercostal muscle produced tissue deformation and failure with no detectable change in the amplitude or frequency of the background sound during tensile loading. The other specimens failed before reaching the same levels of tensile load. Further studies are required in order to address the numerous limitations of this study.

\section{*CORRESPONDING AUTHOR}

Dr. Arjan Buis, Department of Biomedical Engineering, University of Strathclyde, Wolfson Centre, 106 Rottenrow, Glasgow, G4 0NW, Scotland, UK.

ORCID number: https://orcid.org/0000-0003-3947-293X

Email: arjan.buis@ strath.ac.uk

DOI: https://doi.org/10.33137/cpoj.v1i1.30354

\section{ARTICLE INFO}

Received: May 08, 2018

Accepted: August 24, 2018

Published: August 28, 2018

\section{CITATION}

Buis A, Guarato F, Law J, Ralston Z, Courtney A. A feasibility study to investigate if there is a correlation between soft tissue deformation and acoustic emission. Canadian Prosthetics \& Orthotics Journal, Volume 1, Issue 1, No 5, 2018.

\section{KEYWORDS}

Prosthetics, Acoustic Emission, Deep Tissue Injury, Pressure Ulcer, Tissue Shear, Prosthetic Socket Design, Diabetic Foot, Soft Tissue, Lower Limb Prosthetic, Tensile Load.

\section{ABBREVIATIONS}

AE : Acoustic Emission

DTI : Deep Tissue Injury

DPU: Deep Pressure Ulcers 


\section{INTRODUCTION}

In the UK, $72 \%$ of lower limb amputations result from dysvascularity and/or neuropathy, with the majority of amputations occurring at trans-tibial level (1). The two commonly used trans-tibial socket designs are based on conflicting principles, both of which have a lack of substantiation regarding the internal conditions of the residual limb within the socket (2). The first design, the PTB socket, applies specific loads to pressure-tolerant areas, whereas the hydrocast socket aims to dispense pressure uniformly through the "stiffest path principle" (3). It is advocated that hydrocast sockets have a greater ability to generate "ideal" pressure distribution together with a reduction in internal shear (2).There is, at present, no consensus on what defines an "optimal" socket design or fit $(3,4)$.

There is a growing belief among researchers that the 'coupling' stiffness between the hard prosthetic socket and the weight bearing structure, the skeleton, is a major factor in optimising the quality of a socket design $(3,5)$, as it can reduce the amount of tissue deformation during load bearing and consequently reduce the shear stresses in the soft tissues (3-5). Due to the aetiology of these amputations, the residual limb is at increased risk of developing a deep tissue injury (DTI) due to peripheral neuropathy, impaired blood supply and/or poor skin condition (6). If a DTI is misdiagnosed or diagnosed late in this population, there can be a risk of revision amputation being necessary due to increasing tissue necrosis. This severely impacts the patient's quality of life and places excess strain on the healthcare system (7). This highlights the avid prerequisite for comprehensive assessment of prosthetic socket fit and function.

To date, research focusing on residuum-socket interface pressures has been unable to establish a direct relationship between interface pressures and the magnitude of deep tissue stresses. These studies have inadequately quantified the mechanical stresses within deep internal tissues $(8,9)$. As a result, interfacial pressures alone are unlikely to change socket design principles and additional performance/bio- markers are therefore needed.

\section{Deep Tissue Injury (DTI)}

Ulceration as a direct result of pressure can be characterised into six differing classifications according to the National Pressure Ulcer Advisory Panel. However, they are broadly divided into two groups: superficial or deep (10). Superficial ulcers can be triggered by a variety of mechanisms, including a combination of moisture and heat, in conjunction with frictional and shear forces, infection, poor nutrition and/or peripheral neuropathy $(8,10-12)$. These ulcers are confined to the epidermis, can be identified by visual inspection of the skin (10) and have been confirmed reversible $(8,13)$.

On the contrary, deep pressure ulcers (DPUs) are secondary to DTIs and have a different mechanism of origin (8). The term DTI designates an ulcer that experiences high pressure at the bone-muscle interface, below intact skin $(11,13)$. A DTI can have the visual appearance of a deep bruise and can often be mistaken for a superficial pressure ulcer, resulting in appropriate diagnosis often occurring at a late stage $(6,8,10)$. As deep skeletal muscle undergoes necrosis secondary to pressure, it begins to stiffen which transfers the stresses to more superficial layers of tissue $(8,9,12)$. As a result, necrotic tissue will develop in these superficial layers continuing the positive-feedback cycle of muscle stiffening and tissue necrosis until the ulcer appears on the epidermal layer $(8,12)$. Exemplar situations in which DTIs can often occur include immobile patients in bed, wheelchair bound patients or users of orthoses/prostheses - the primary focus of this study (14, $15)$.

DTI's have historically been alleged to be instigated by factors which can include pressure-related ischaemia and/or ischaemia-reperfusion injuries due to the quick flow of blood rushing back to ischaemic tissues upon withdrawal of the applied load $(6,8,11,13,16,17)$. However, more contemporary studies suggest that tissue deformation and ischaemia related deformation injuries can also contribute to a DTI (13) . Interestingly, it has been shown that tissue deformation results in permanent muscle damage following two hours of compressive loading whereas muscle damage due to ischaemia can be reversible $(14,17)$. This information highlights the necessity of imminent investigation regarding the compression of soft tissues and the applied deformation forces on soft tissues, in order to reduce the risk of a DTI.

Portnoy et al assessed the specific forces acting on a transtibial residuum and analysed the internal 
mechanical condition of the soft tissues during static weight bearing. They established that in a transtibial residuum, soft tissues are subject to tensile, compressive and both internal and external shear forces during static and dynamic loading. It was concluded that the magnitude of tensile and shear strain within the tissues was much greater than the compressive strain (2).

Differing academics seconded this when they demonstrated that DTIs tend to develop in areas where highest shear strain values have been recorded during tissue loading (14) and that tissue damage increases with increasing shear strain (13). Thus, it has been concluded that the force in a transtibial socket most likely to cause a DTI is shear force.

Shear forces can be separated into internal and external categories. Shear can develop when external frictional forces stretch the top layer of the skin as it slides against a supporting surface (e.g. against a bone or against a prosthetic socket) $(18,19)$. This theory can then be applied to internal shear forces where subcutaneous tissue and muscle glide over one another. Internal and external shear forces interact. For example, the presence of internal shear increases around the ischial tuberosities where the skin has been stretched. This type of shear is commonly seen in pressure ulcer formation, especially around the sacrum, however, this can occur on any part of the body. Both external frictional forces and internal tissue shear contribute to the six certified classifications of pressure ulcers, however, these two forces are more significant in DTIs than in superficial ulcers (18).

Contemporary publications exploring socket fit have utilised sensors in order to research socket-interface pressures in transtibial users (20). However, it is now recognised that the condition of the deep muscle tissue is not accounted for in these studies and that the close proximity of the deep vascular structures to bony prominences is likely to result in much higher pressures than present on the surface of the residuum (8). Therefore, the sole use of interface sensors at the skin's surface is inadequate in detecting high pressures at the bone-muscle interface. Consequently, this method does not highlight DTI risk and thus, does not truly quantify conclusive results with regard to an 'optimal socket fit'.

Detection of DTI's could therefore be used as an aid to assess the biomechanical fit of a prosthetic socket, along with other methods, using tissue deformation as a parameter of measurement.

\section{Measurement of DTI in Clinical Practice}

At present, there are several current clinical techniques which have a body of supporting research substantiating their usage in the detection of DTIs. However, these current methods prove to be invasive (serum chemistry), provide latent information i.e. not real time (urine and serum chemistry along with MRI), expensive (MRI) or require specialist knowledge to interpret (sonography and MRI). Currently, sonography seems most promising in DTI detection due to portability and economic factors, however, further research is required to define the specific characteristics.

Another possible method of detecting the presence of a DTI, which holds pre-empted potential, may be to analyse acoustic emission (AE) that may arise from shear stress.

When an external load is applied to a material, deformation occurs as a result of the relative movement between atomic chains, with this movement emitting acoustic waves $(21,22)$. The phenomenon is known as $\mathrm{AE}$ and currently has well established applications in structural and civil engineering. $\mathrm{AE}$ detection is classified as a non-destructive and a non-invasive realtime method to assess the integrity of the internal structure of a material (21-23). It does not require an input signal as the acoustic waves are generated by the material and transducers can be placed anywhere on the materials surface to monitor acoustic output (22). However, the detection of AE may be affected by background noise and there is potential for the signal to be distorted as it propagates through a material. Therefore, mechanically advanced microphones may be obligatory in order to accurately capture the signals (21, 23).

Sound waves are released as muscle contracts/is loaded and these waves may then be detected using acoustic myography (AMG), a specialised AE technique (2428). It is believed that the noise arises from the lateral oscillations of fibres $(24,28,29)$. Interestingly, the contractile force is proportional to the volume of the acoustic noise $(24,25)$. This signal has been utilised, by adapting AMG, to analyse muscle activity and fatigue $(24,26,28,29)$ and to control an externally powered upper limb prosthesis (27). The movement which occurs 
within muscle tissue during deformation could potentially release $\mathrm{AE}$ waves as atomic dislocations produce pressure waves that travel through the tissue and are detectable on the surface $(23,24)$. Tendons and skeletal muscles that are composed of uni-directional fibres have the potential to develop shear stresses when these tissues are loaded multi-directionally (30), which can be identified by AE.

\section{Research Hypothesis and Objectives}

The objectives of this study are to firstly select a microphone suitable for this experimental work to enable simultaneous recording of acoustic frequencies and deformation data from tissue specimens under tensile loading, to visually examine data for acoustic peaks at critical points in the deformation data collected and then to present the results with future recommendations. This study hypothesizes that acoustic signals are emitted from skeletal muscle tissue when it is deformed during loading.

\section{METHODS}

\section{Specimens and Equipment}

Two baseline tests were carried out using a sample of fabric webbing. This style of webbing was selected as it is manufactured from a weaved structure composing of uni-directional fibers with low elasticity - crudely comparable with soft tissue. The tensile testing was performed with an Instron testing machine (Electropuls $^{\mathrm{TM}}$ E10000) and allowed to exercise a displacement control test. This means that the tissue under investigation is stretched with a selected loading rate samples were loaded under tension $(1 \mathrm{~mm} / \mathrm{s}$ to $20 \mathrm{~mm}$ ) and simultaneous length increase is recorded.

Biological test specimens firstly included intercostal muscle and bone from sus scrofa domesticus (pork). Additionally, domensticus (chicken) was selected, ensuring the muscle belly of the gastronomicus and its attachment to bone was intact. Bone was utilised in order to maintain tissue structure throughout testing (Figure1). These biological test specimens were selected due to the organized uni-directional nature of the fibers and the ease of availability. The specimens were dissected when the muscle was frozen, however, due, to the initial freezing process, the muscles were contorted and had to be thawed and refrozen into a more easily dissectible state. The specimens were thawed at room temperature prior to testing. Samples were prepared by isolating the muscle and cutting the bone at the attachment points into a size suitable for the clamps to receive (Figure 2), with an approximate width of $1 \mathrm{~cm}$ per unit. Bone was used as a clamping point to minimise slippage during testing.

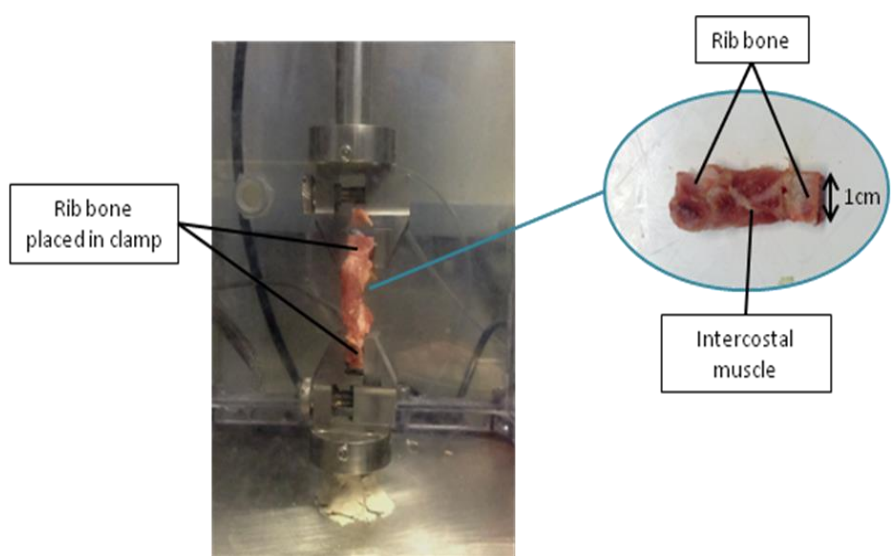

Figure1. Pork specimen clamped in bath via rib bones. Enlarged view of specimen illustrating preparation and size of sample.

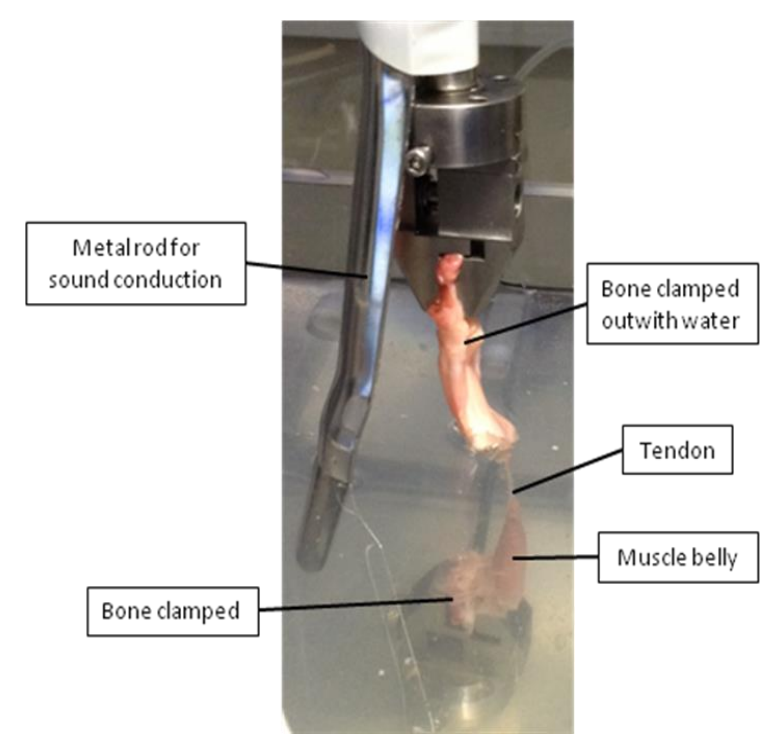

Figure 2. View looking downwards into bath with chicken specimen clamped in place (Test 1). As part of specimen was clamped out with the bath, a rod was used to conduct the "tapping" signal to synchronise data collection.

An Instron testing machine (Electropuls ${ }^{\mathrm{TM}}$ E10000) with a $1 \mathrm{kN}$ load cell was used to apply a tensile force to each specimen. Specimens were clamped onto serrated grips and submerged in a physiological saline solution (Composition: $0.9 \mathrm{~g}$ sodium chloride - Purified water QS $100 \mathrm{ml}$ ) bath $(30 \mathrm{~mm} \times 30 \mathrm{~mm} \times 30 \mathrm{~mm})$ to simulate an in vitro environment (Figure 3). As sound 
propagates through liquid at a faster rate than through air, the test environment was anticipated to aid acoustic detection, providing an improved medium for the hydrophone. Unfortunately, the temperature of the saline could not be controlled in this study due to the customisation of the test equipment.

An omni-directional hydrophone with an inbuilt preamplifier was placed within the bath to detect acoustic signals. The selected hydrophone had a frequency range of $0.1 \mathrm{~Hz}-180 \mathrm{kHz}$ (Bruel and Kjaer Type 8103 ) and a voltage sensitivity of $25.4 \mu \mathrm{V} / \mathrm{Pa}$. The sensitivity range of the Hydrophone is within the acoustic range between $20 \mathrm{~Hz}$ and $20 \mathrm{KHz}$ as illustrated in Figure 4 and capable to operate in the target range.

The hydrophone was consistently positioned $10 \mathrm{~mm}$ from the tissue under analysis. A digital oscilloscope (Gratten GA1000CAL) recorded hydrophone data in real-time and had a sampling rate of $40 \mathrm{MHz}$.

The Instron and hydrophone data were recorded simultaneously with the load cell "tapped" at the beginning of each test to act as a data synchronisation point.

\section{Test Protocols}

WaveMatrix ${ }^{\mathrm{TM}}$ software gathered time, load and displacement data at a sampling rate of $1000 \mathrm{~Hz}$. The amplitude of the acoustic signal was recorded on the oscilloscope with a sampling rate of $40 \mathrm{MHz}$. Microsoft Excel $^{\mathrm{TM}}$ was used to generate graphical representations of the WaveMatrix ${ }^{\mathrm{TM}}$ data. The oscilloscope captured amplitude information which was imported to MatLab allowing for signal processing in the frequency and time domain by applying the Fourier transform to the full data set:

$$
X(k)=\sum_{j=1}^{N} x(j) \omega_{N}^{-(j-1)(k-1)}
$$

where, $\omega_{N}=e^{(-2 \pi i) / N}$

There is a lack of current available evidence to support the optimal tensile displacement rate and threshold during testing, as studies commonly select 1, 5 and $10 \mathrm{~mm} / \mathrm{s}$ for tissue compression rates with no apparent justification $(31,32)$. In this study, displacement rate and threshold was restricted by the collection of realtime acoustic data from the oscilloscope display.

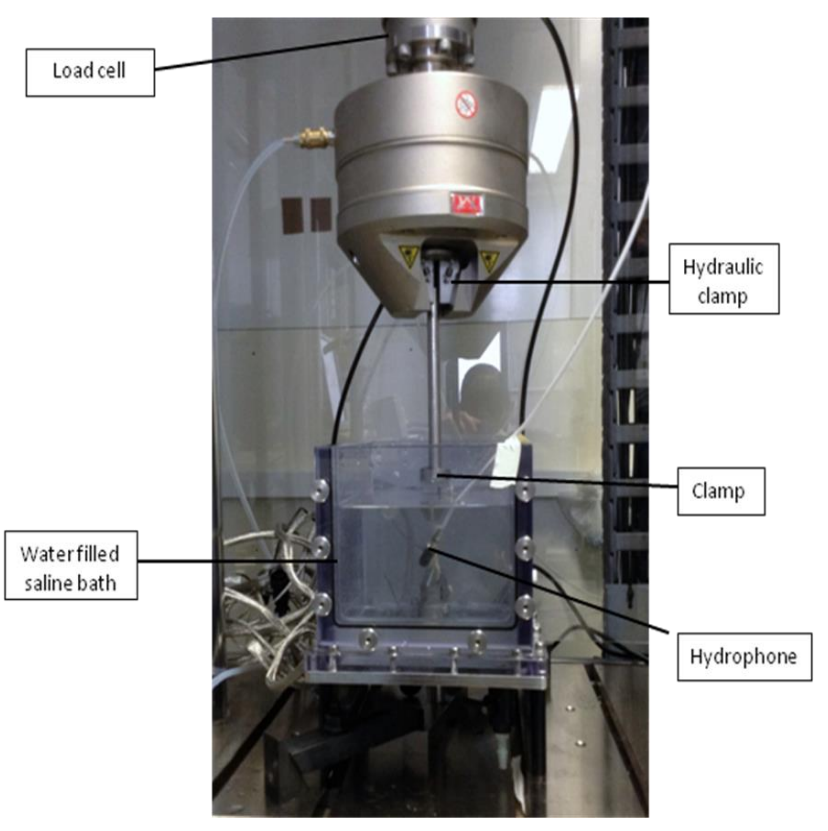

Figure 3. Instron test machine setup including saline bath and hydrophone.

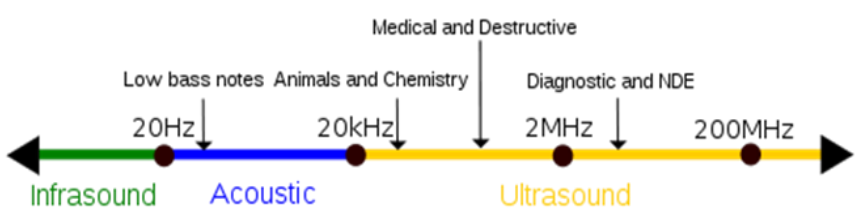

Figure 4. Sound frequency spectrum.

Two baseline tests with fabric webbing were conducted at a ramp rate of $1 \mathrm{~mm} / \mathrm{s}$ to a total displacement of $20 \mathrm{~mm}$ by a tensile load. One sus scrofa domesticus sample and three gallus gallus domesticus samples were loaded under tension at $1 \mathrm{~mm} / \mathrm{s}$ to $20 \mathrm{~mm} / \mathrm{s}$. WaveMatrix ${ }^{\mathrm{TM}}$ software was instructed to collect data for 2 seconds prior to the commencement of displacement to allow the "tapping" of the load cell to be recorded.

\section{RESULTS}

Tests with three different tissues have been conducted but not all have been successful. The narrative will describe the tests that were disregarded and the main body of the result section will describe the tests used for analysis. 


\section{Narrative}

A baseline test with a fabric with uni-directional fiber orientation, followed by experiments using animal specimen, Sus scrofa domesticus (pork) and Gallus gallus domensticus (chicken) respectively. During the first tests utilising the fabric specimen, the specimen slipped in the clamp which disturbed the recording and were disregarded. During tensile testing of the pork intercostal muscle specimen, the tissue failed by detaching from the bone. The chicken specimen utilised for test 2 slipped in the clamp during testing, being subject to a maximum load of $18 \mathrm{~N}$ and was omitted from the data set.

\section{Baseline}

In test 2 , the fabric failed after approximately $7 \mathrm{~s}$ at a tensile load of $112 \mathrm{~N}$ and at a displacement of $8 \mathrm{~mm}$ (Figure 5).

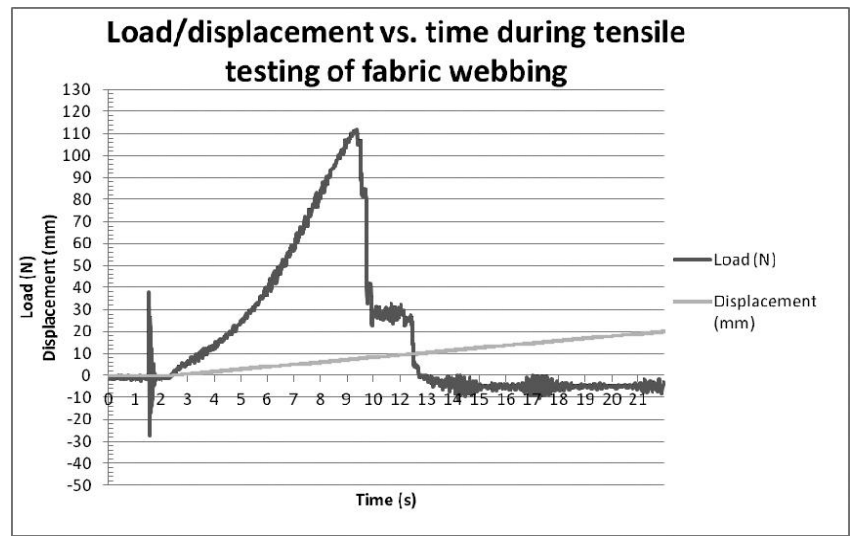

Figure5. Plot of load and displacement against time of baseline test 2 using fabric webbing. Initial data spike from "tapping" of load cell for data synchronisation point clearly captured.

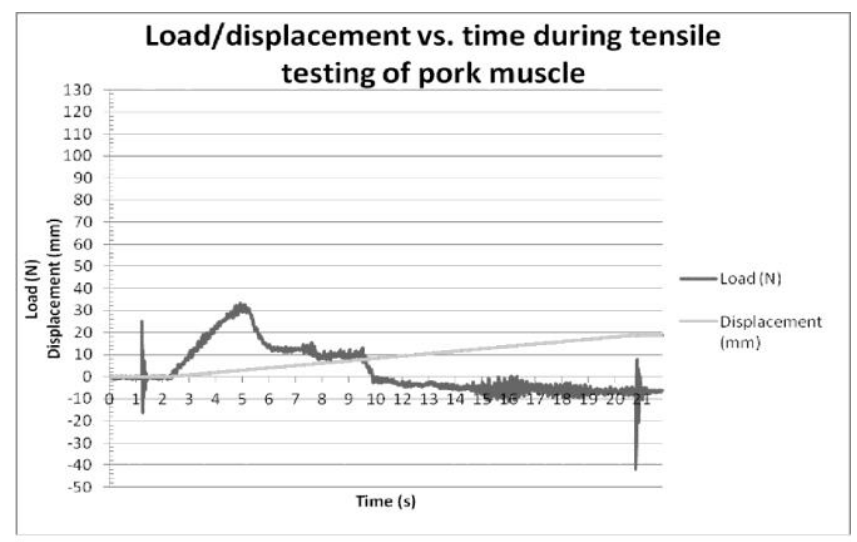

Figure 6. Load/displacement against time of pork intercostal muscle under tensile load resulting in specimen failure at 34 $\mathrm{N}$.

\section{Sus scrofa domesticus Testing}

The inter-costal muscle failed after 3 seconds at a load of $34 \mathrm{~N}$ and a displacement of $3 \mathrm{~mm}$ (Figure 6).

\section{Gallus gallus domensticus Testing}

In test 1 with chicken muscle, the muscle bulk was entirely submerged in the bath, however, one end of the bone lay out with the bath due to the specimen size (Figure 2). As part of the specimen lay out with the bath, a rod was used to conduct the "tapping" signal in order to synchronise data collection. This specimen successfully completed testing without fail and experienced a maximum load of $13 \mathrm{~N}$.

The specimen utilised for test 2 comprised of a larger muscle belly which also lay out with the dimensions of the bath. In test 3 , the specimen failed after $18.3 \mathrm{~s}$ at a displacement of $16 \mathrm{~mm}$ (Figure 7) as the tendon became detached from bone. The peak load applied to the specimen was $20 \mathrm{~N}$, occurring at $12 \mathrm{~s}$.

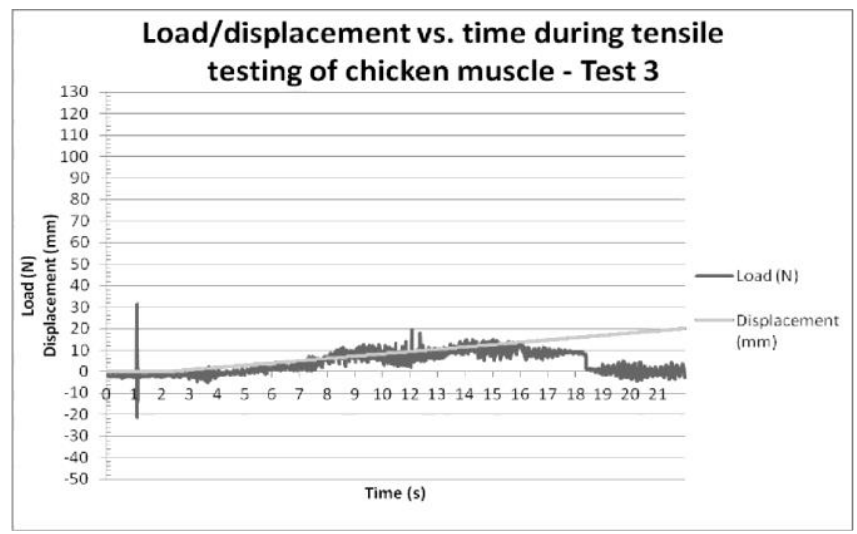

Figure 7. Load /displacement against time during test 3 on chicken tissue in which specimen failed.

\section{Acoustic Emission data}

In both the fabric and the chicken specimens, the acoustic data collected during testing did not include enough data points. This resulted in inadequate findings on these samples. Thus, acoustic data could only be analysed on the sole pork specimen. The amplitude recording (Figure 8 and 9) detected the sound created by the "tapping" signal, with only the trace of background noise before and during the tensile testing phase. Figure 10 shows a plot of amplitude and frequency (Figure 10). 


\section{DISCUSSION}

This study investigated the hypothesis that animal soft tissue emits acoustic noise when subject to deformation from an externally applied load. Due to the limited number of trials performed in this study, statistical analysis could not be performed.

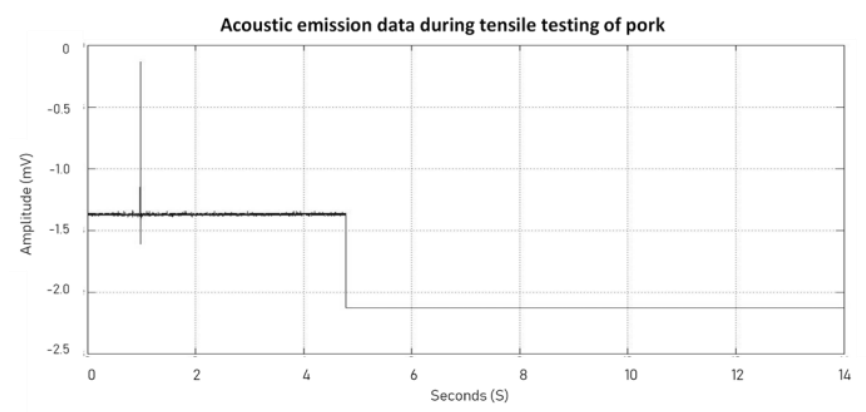

Figure 8. Amplitude against time (s) of tensile test on pork specimen. Data spike from "tapping" of load cell clearly displayed.

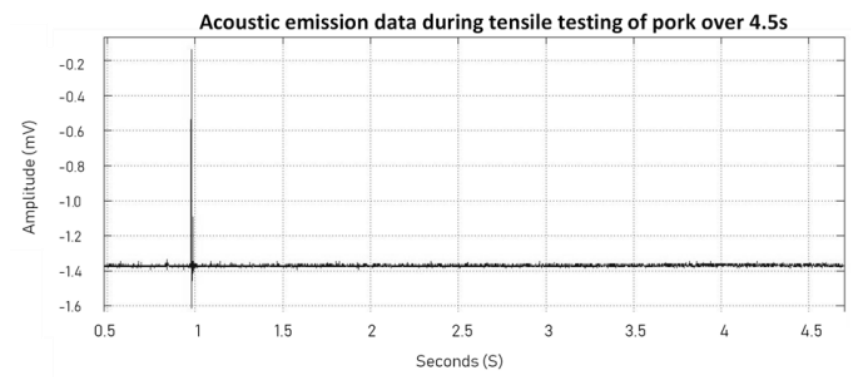

Figure 9. Zoomed in display of amplitude against time (s) for tensile test on pork specimen. This illustrates the absence of any sound which may be associated with deformation of the specimen.

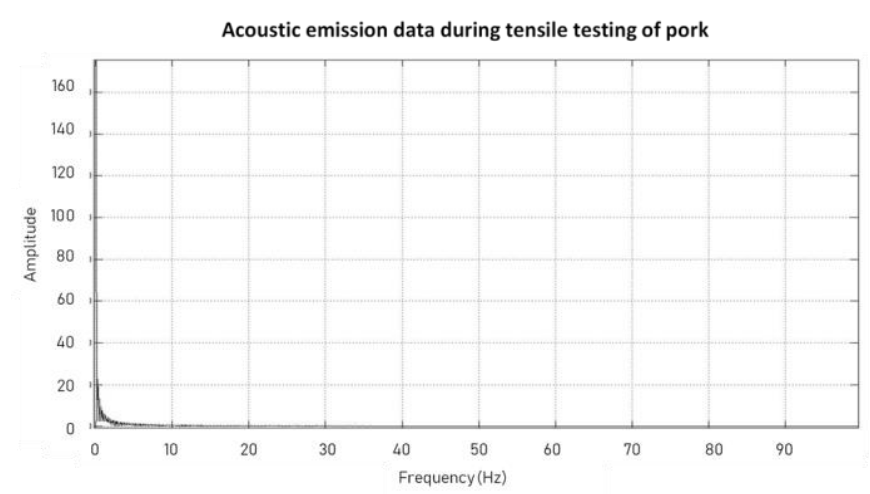

Figure 10. Plot of amplitude against frequency for pork specimen showing no discernible change in frequency of the recorded signal.

During testing of the pork intercostal muscle specimen, failure occurred as the soft tissue detached from the bone, thus indicating tissue deformation was likely taking place at the bony attachment and not within the muscle bulk. As a result, further testing on these specimens was not conducted.

In the limited data collected for these samples, no event occurred in the acoustic data to indicate tissue was being deformed or failed. The only event clearly captured in either the amplitude or frequency reading was the "tapping" of the load cell which was required in order to synchronise the data.

The above results also highlight that during experimentation of the chicken tissue, inconclusive results were collected and thus no correlation could be explored. However, as the maximum load measured during testing of pork $(35 \mathrm{~N})$ was higher than that recorded on any of the tests on chicken $(20 \mathrm{~N})$, it may be postulated that no correlation would be seen between the acoustic output and tissue deformation in these tests either.

The fabric webbing failed at a load of $112 \mathrm{~N}$. $112 \mathrm{~N}$ may have been a high enough load to produce an $\mathrm{AE}$ data recording reading, however, unfortunately there was no recoding in this study. These results are therefore unable to indicate a correlation between tissue deformation and emission of an acoustic signal.

Though the Instron testing machine applied a tensile loading force in this feasibility study, this is not the same as shear, which, as previously mentioned, has an important role in DTI development $(13,14,18)$. However, it may be assumed that internal shear stresses were present during tensile loading, as the pressure gradient induced by the tensile loading may give rise to internal shear stresses $(3,5,24)$.

There were several limitations to this feasibility study. A degree of slippage was noted between each specimen and the clamps during loading. Consequently, the specimens may not fully subjected to the applied load.

The interaction between skeletal muscle and other biological tissues was not taken into account in this study, as the aim was to investigate whether or not acoustic signals are emitted from isolated skeletal muscle undergoing deformation. Future work would be required to investigate this phenomenon in a cadaveric limb segment. 
It may not be appropriate to extrapolate in vitro results to the in vivo environment due to the large number of assumptions encountered and the complexity of muscle structure. Most biological tissues (including skeletal muscle and connective tissue) are described as viscoelastic in nature $(3,5,33)$. This means they exhibit both viscous (i.e. fluid-like behavior resisting shear) and elastic (i.e. rapidly returning to original state) characteristics when strained. Specifically, with muscle it displays elasticity when it returns to its original shape when stretched then released (34). A muscle's viscosity is the internal resistance to motion (35). As a result of this, viscoelasticity time is also an important factor as viscosity dissipates the shear force $(32,36)$. This is further corroborated by porcine muscle displaying different levels of stress to a variety of strain rates (34). Considering the loading of a trans-tibial residual limb during ambulation with a prosthesis, the residuum will be subject to tensile, compressive and shear forces simultaneously and in a cyclic manner. The residual limb is loaded for $62 \%$ of the gait cycle (37) but it will also be subject to external forces during swing phase due to the inertia of the swinging limb. The vertical displacement of the tibia due to socket pistoning during the gait cycle has been investigated in many studies (3840 ) with the mean value of the collective movement in the proximodistal direction throughout a full gait cycle being $57 \mathrm{~mm}$ while using a patellar-tendon bearing socket (40). The relative movement between the tibia and the surrounding soft tissue will lead to tissue deformation. However, tibial movement not only occurs in the coronal plane but also in the sagittal plane, so deforming forces are being applied to various locations on the residuum and in different directions. Thus, in amputees, DTI is more likely to occur over long periods of cyclical gait motion in a multi-directional orientation. If it were possible to record acoustic data over a longer period of time, a slower more realistic strain rate could be employed along with compression testing to recreate forces experienced by the residual limb.

The values chosen for this study were not based on quantitative evidence (due to a significant lack of literature investigating the loading rates of internal soft tissue in a residual limb during gait) but on values selected in preceding studies in which tissue damage was examined through displacement $(31,32)$.
Furthermore, the results presented in this feasibility study are not statistically significant as a very limited number of tests were conducted. It has also been noted that this study did not investigate a range of tissue loading rates and thus future work would preferably investigate these as well as cyclic loading conditions. Moreover, the sample numbers collected from the acoustic data in this study did not allow for sufficient examination of the correlation between tissue deformation and acoustic output.

Another point of note is that, ideally, biological specimens should be prepared and tested within a few hours of death to preserve the mechanical properties. It has been documented that freezing muscle alters and reduces its strength (41). In contrast, Huang et al has documented that thawing then refreezing tendon in less than three cycles does not significantly alter the mechanical properties (42). Despite these conflicting findings, biological tissue should be tested fresh if possible or it should be preserved in a manner that reflects the in vivo environment with minimum freezing.

An alternative transducer may be a contact microphone which is placed on the surface of the material being tested. The inclusion of a pre-amplifier may also enhance the detection of any sound signal being emitted. Further investigation is required to carry out a robust correlation analysis between tissue deformation and acoustic emission. This would ideally incorporate a variety of transducers to detect sound output, testing of various tissues and the application of a range of tissue displacement rates.

The acoustic emission of tissue under shear is most likely be over shadowed by muscle noise and sliding tissues during human movement (mechanomyogram (MMG)). In addition, the noise generated by the prosthetic intervention itself and contact with clothing will in all probability render a clinical application useless.

\section{CONCLUSIONS}

This feasibility study provides a foundation of results regarding tissue deformation and AE. Results displayed that tensile testing of pork intercostal muscle produced tissue deformation and failure with no detectable change in the amplitude or frequency of the background sound 
during tensile loading. There is a more than strong argument that acoustic shear emission during soft tissue deformation is over shadowed by muscle activation noise (MMG) and noise generated in the prosthetic system during gait.

The other specimens failed before reaching the same levels of tensile load, and, as testing of other tissue did not reach the same levels of tensile load, it is unlikely that any acoustic events could have been detected from these specimens either. Further studies are required in order to address the numerous limitations of this study.

\section{DECLARATION OF CONFLICTING INTERESTS}

No conflict of interest declared. This research did not receive any specific grant from funding agencies in the public, commercial, or not-for-profit sectors.

\section{COMPETING INTERESTS}

None declared

\section{SOURCES OF SUPPORT}

University of Strathclyde - experimental work took place on campus.

\section{ETHICAL APPROVAL}

Not required

\section{AUTHOR CONTRIBUTION}

Arjan Buis: Conceptualization, formal analysis, investigation, methodology, visualization, writing original, review \& editing.

Francesco Guarato: Conceptualization, formal analysis, investigation, methodology, visualization.

Jason Law: formal analysis, investigation, methodology, visualization, writing original.

Zoe Ralston: formal analysis, investigation, methodology, visualization, writing original.

Anna Courtney: methodology, visualization, Writing original. review \& editing.

\section{REFERENCES}

1. National Amputee Statistical Database (NASDAB). The Amputee Statistical Database for the United Kingdom. Edinburgh: Information Services Division, NHSScotland, 2006/07.
2. Portnoy S, Yizhar Z, Shabshin N, Itzchak Y, Kristal A, Dotan-Marom $Y$, et al. Internal mechanical conditions in the soft tissues of a residual limb of a trans-tibial amputee. Journal of Biomechanics. 2008;41(9):1897-1909. DOI: 10.1016/j.jbiomech.2008.03.035.

3. Klasson B, Buis, AWP. Prosthetic Socket Fit; Implications of basic engineering principles. 94912 Advanced prosthetic science (manual 3): NCPO, University of Strathclyde, Glasgow; 2006.

4. Mak AF, Zhang M, Boone DA. State-of-the-art research in lower-limb prosthetic biomechanics-socket interface: a review. Journal of rehabilitation research and development. 2001;38(2):161-174.

5. Klasson B, Buis A. Appreciation of prosthetic socket fitting from basic engineering principles. National Centre for Training and Education in Prosthetics and Orthotics, University of Strathclyde, 1995.

6. Portnoy S, Siev-Ner I, Shabshin N, Kristal A, Yizhar Z, Gefen A. Patient-specific analyses of deep tissue loads post transtibial amputation in residual limbs of multiple prosthetic users. Journal of Biomechanics. 2009;42(16):2686-2693. DOI: $10.1016 /$ j.jbiomech.2009. 08.019.

7. Saluwa A, Middleton C, Gilbertson A, Kodavali K, Neumann V. Stump ulcers and continued prosthetic limb use. Prosthetic and Orthotics International. 2006;30(3): 279-285. DOI.org/10.1080/03093640600836139.

8. Gefen A, Levine J. The false premise in measuring bodysupport interface pressures for preventing serious pressure ulcers. Journal of medical engineering \& technology. 2007; 31(5), 375-380. DOI.org/10.1080/03091900601165256.

9. Yarnitzky G, Yizhar Z, Gefen A. Real-time subjectspecific monitoring of internal deformations and stresses in the soft tissues of the foot: A new approach in gait analysis. Journal of Biomechanics. 2006;39(14):2673-2689. DOI: 10.1016/j.jbiomech.2005.08.021.

10. NPUAP, EPUAP. Treatment of pressure ulcers: quick reference guide. Washington DC: National Pressure Ulcer Advisory Panel; 2009.

11. Mak AFT, Yu Y, Kwan LPC, Sun L, Tam EWC. Deformation and reperfusion damages and their accumulation in subcutaneous tissues during loading and unloading: A theoretical modeling of deep tissue injuries. Journal of Theoretical Biology. 2011;289(0):65. DOI: 10.1016/j.jtbi.2011.08.022.

12. Gefen A, Gefen N, Linder-ganz E, Margulies SS. In vivo muscle stiffening under bone compression promotes deep pressure sores. Journal of biomechanical engineering. 2005; 127(3), 512-524. DOI: 10.1115/1.1894386. 
13. Ceelen KK, Stekelenburg A, Loerakker S, Strijkers GJ, Bader DL, Nicolay K, et al. Compression-induced damage and internal tissue strains are related. Journal of Biomechanics. 2008;41(16):3399-3404. DOI: 10.1016/j.jbiomech.2008.09.016

14. Stekelenburg A, Strijkers G, Parusel H, Bader DL, Nicolay K, Oomens CW. Role of ischemia and deformation in the onset of compression-induced deep tissue injury: MRIbased studies in a rat model. Journal of Applied Physiology. 2007;102(5):2002-2011.

DOI.org/10.1152/japplphysiol.01115.2006.

15. Bansal C, Scott R, Stewart D, Cockerell CJ. Decubitus ulcers: a review of the literature. International Journal of Dermatology. 2005;44(10):805-810. DOI: $10.1111 / \mathrm{j} .1365-$ 4632.2005.02636.x.

16. Gefen A, van Nierop B, Bader DL, Oomens CW. Straintime cell-death threshold for skeletal muscle in a tissueengineered model system for deep tissue injury. Journal of Biomechanics. 2008;41(9):2003-2012. DOI: 10.1016/j.jbiomech.2008.03.039.

17. Stekelenburg A, Gawlitta D, Bader DL, Oomens CW. Deep Tissue Injury: How Deep is Our Understanding? Archives of Physical Medicine and Rehabilitation. 2008;89(7):1410-1413.

DOI.org/10.1016/j.apmr.2008.01.012

18. Gefen A, Farid K, Shaywitz I. A Review of Deep Tissue Injury Development, Detection and Prevention: Shear Savvy. Ostomy Wound Management. 2013;59(2):26-35.

19. Gefen A. Risk factors for a pressure-related deep tissue injury: a theoretical model. Medical \& Biological Engineering \& Computing. 2007;45(6):563-573. DOI: 10.1007/s11517-007-0187-9.

20. Courtney A, Orendurff MS, Buis A. Effect of alignment perturbations in a trans-tibial prosthesis user: a pilot study. Journal of Rehabilitation Medicine. 2016; 22;48(4):396-401. DOI.org/10.2340/16501977-2075.

21. Williams RV. Acoustic emission. Adam Hilger, Bristol. 1980:116.

22. Kohn DH. Acoustic emission and non-destructive evaluation of biomaterials and tissues. Critical reviews in biomedical engineering. 1995;23(3-4):221-306. DOI: 10.1615/CritRevBiomedEng.v23.i3-4.20.

23. Thomas IM. Acoustic emission as a technique for monitoring failure within vertebral bodies. Glasgow: University of Strathclyde; 1986.

24. Stokes M, Dalton PA. Acoustic myography for investigating human skeletal-muscle fatigue. Journal Of Applied Physiology, 1991;71(4):1422-1426. DOI: 10.1152/jappl.1991.71.4.1422.
25. Islam A, Sundaraj K, Ahmad B, Ahamed N, Ali A. Mechanomyography Sensors for Muscle Assessment: a Brief Review. Journal of Physical Therapy Science.2012; 13591365. DOI.org/10.1589/jpts.24.1359.

26. Barry DT, Geiringer SR, Ball RD. Acoustic myography: a noninvasive monitor of motor unit fatigue. Muscle \& nerve. 1985;8(3):189-194. DOI:10.1002/mus.880080303.

27. Barry DT, Leonard JA, Gitter AJ, Ball RD. Acoustic myography as a control signal for an externally powered prosthesis. Archives of physical medicine and rehabilitation. 1986;67(4):267-269.

28. Barry D, Cole N. Muscle sounds are emitted at the resonant frequencies of skeletal- muscle. IEEE. Transactions On Biomedical Engineering. 1990;37(5):525-531. DOI: 10.1109/10.55644.

29. Frangioni JV, Kwan-Gett TS, Dobrunz LE, McMahon TA. The mechanism of low- frequency sound production in muscle. Biophysical Journal. 1987;51(5):775-783. DOI: 10.1016/S0006-3495(87)83404-5.

30. Buis A, McGarry A, Gachagan A, Riches P. Acoustic emission, detection and analysis of deep tissue injury (DTI) in trans-tibial prosthetic sockets (Research Proposal). University of Strathclyde: AOPA; 2011.

31. Tonuk E, Silver-Thorn MB. Nonlinear elastic material property estimation of lower extremity residual limb tissues. IEEE Transactions on Neural Systems and Rehabilitation Engineering. $\quad 2003 ; 11(1): 43-53$. DOI: 10.1109/TNSRE.2003.810436.

32. Silver-Thorn MB. In vivo indentation of lower extremity limb soft tissues. IEEE Transactions on Rehabilitation Engineering. 1999;7(3):268-277. DOI: 10.1109/86.788464.

33. Lieber RL, Leonard ME, Brown-Maupin CG. Effects of Muscle Contraction on the Load- Strain Properties of Frog Aponeurosis and Tendon. Cells Tissues Organs. 2000;166(1):48-54. DOI:10.1159/000016708.

34. Nie X, Cheng J, Chen W, Weerasooriya T. Dynamic Tensile Response of Porcine Muscle. Journal Of Applied Mechanics-Transactions Of The Asme. 2011;78(2)-78. doi:10.1115/1.4002580.

35. Nihat Oz. Fundamentals of biomechanics : equilibrium, motion, and deformation. Margareta N, editor. New York: New York: Springer; 1999.

36. Christensen RM. Theory of viscoelasticity: an introduction. New York: New York: Academix Press; 1971.

37. Sanders JE, Daly CH, Burgess EM. Clinical measurement of normal and shear stresses on a trans-tibial stump: characteristics of wave-form shapes during walking. 
Prosthetics and orthotics international. 1993;17(1):38-48. DOI.org/10.3109/03093649309164353.

38. Grevsten S, Erikson U. A roentgenological study of the stump-socket contact and skeletal displacement in the PTBsuction prosthesis. Upsala Journal of Medical Sciences, 1975;80(1):49-57. DOI.org/10.3109/03009737509178991

39. Narita H, Yokogushi K, Shii S, Kakizawa M, Nosaka T. Suspension effect and dynamic evaluation of the total surface bearing (TSB) trans-tibial prosthesis: a comparison with the patellar tendon bearing (PTB) trans-tibial prosthesis. Prosthetics and orthotics International. 1997;21(3):175-178. DOI:10.3109/03093649709164551.

40. Lilja M, Johansson T, Oberg T. Movement of the tibial end in a PTB prosthesis socket: a sagittal X-ray study of the PTB prosthesis. Prosthetics and orthotics International. 1993;17(1):21-26. DOI:10.3109/03093649309164351.

41. Gottsauner-Wolf F, Grabowski JJ, Chao EY, An KN. Effects of freeze/thaw conditioning on the tensile properties and failure mode of bone-muscle- bone units: a biomechanical and histological study in dogs. Journal of orthopaedic research : official publication of the Orthopaedic Research Society. 1995;13(1):90-95. DOI: 10.1002/jor.1100130114.

42. Huang H, Zhang J, Sun K, Zhang X, Tian S. Effects of repetitive multiple freeze-thaw cycles on the biomechanical properties of human flexor digitorum superficialis and flexor pollicis longus tendons. Clinical biomechanics (Bristol, Avon), 2011;26(4):419-23.

DOI: 10.1016/j.clinbiomech.2010.12.006. 